\title{
Retraction Note: The Effect of Magnetic Fields for Laser Welding Process using Carbon Steel
}

\author{
Wooram Lee ${ }^{\#}$ and Chul-Ku Lee
}

(C) 2014 by KSPE and Springer

Retraction Note: Int. J. Precis. Eng. Manuf., Vol. 14, No. 11, pp. 1915-1923, 2013

DOI 10.1007/s12541-013-0260-2

The Editors of International Journal of Precision Engineering and Manufacturing (IJPEM) regret to report that this paper has been retracted due to significant similarity with the following paper published previously: Bachmann, M., Avilov, V., Gumenyuk, A., and Rethmeier, M., About the influence of a steady magnetic field on weld pool dynamics in partial penetration high power laser beam welding of thick aluminium parts, International Journal of Heat and Mass Transfer, Vol. 60, pp. 309-321, 2013. IJPEM follows strict ethical standards and warrants the retraction of any paper that violates these standards.

The online version of the original can be found under doi:10.1007/s12541-013-0260-2

Wooram Lee ${ }^{\#}$ and Chul-Ku Lee

Department of Mechanical and Automotive Engineering, Seoul National University of Science and Technology, Seoul, Republic of Korea

\# E-mail: wooramlee@seoultech.co.kr 